\title{
In-hospital case fatality rates for acute myocardial infarction in Romania
}

\author{
Gabriel Tatu-Chitoiu MD PhD, Mircea Cinteza MD PhD, Maria Dorobantu MD PhD, \\ Mariana Udeanu MD PhD, Olivia Manfrini MD, Carmine Pizzi MD, Marius Vintila MD PhD, \\ Dominic D. Ionescu MD PhD, Elvira Craiu MD PhD, Daniel Burghina MD PhD, Raffaele Bugiardini MD
}

$\infty$ See related research paper by Bobak and Hemingway, page 1190

\section{ABSTRACT}

Background: We describe the clinical characteristics, treatments and in-hospital case-fatality rates in an unselected population of patients admitted for acute myocardial infarction.

Methods: From January 2000 to June 2007, we tracked consecutive patients who were admitted to 7 tertiary referral and 21 county hospitals in Romania for medical treatment of ST-segment elevation acute myocardial infarction. These patients were enrolled in the Romanian Registry for STsegment Elevation Myocardial Infarction. For this prospective study, we collected data on demographic characteristics, cardiovascular risk factors, various aspects of treatment for myocardial infarction, and in-hospital death.

Results: The 9186 patients in the study group had a mean age of 63.8 years. The median time from onset of symptoms to thrombolysis was 230 (interquartile range 120-510) minutes. Of the 9186 patients, 4986 (54.3\%) had hypertension, $1974(21.5 \%)$ had diabetes mellitus, 3545 $(38.6 \%)$ had lipid disorders and $4653(50.7 \%)$ were smokers. The in-hospital mortality rate was $12.7 \%$ (1170 deaths). The study group consisted of 2893 women and 6293 men. The women were older than the men and had higher rates of hypertension and diabetes mellitus but were less likely to be smokers. A smaller proportion of women than men presented within 2 hours after onset of symptoms $(23.1 \%$ v. $34.4 \%, p<0.001)$. Smaller proportions of women received thrombolytics $(40.8 \%$ v. $53.5 \%$, $p<0.001)$, anticoagulants $(93.4 \%$ v. $95.2 \% ; p=0.001)$, antiplatelet agents $(88.3 \%$ v. $91.2 \%, p<0.001)$ and primary percutaneous coronary interventions (1.5\% v. $2.2 \%$, $p=0.030$ ). The risk of in-hospital death was greater for women, even after adjustment for confounders (odds ratio $1.33,95 \%$ confidence interval $1.13-1.56 ; p<0.001)$.

Interpretation: The rates of reperfusion therapy for patients with acute myocardial infarction were low, and in-hospital case-fatality rates were high in this study. Excess in-hospital mortality was more pronounced among women.

Une version française de ce résumé est disponible à l'adresse www.cmaj.ca/cgi/content/full/180/12/1207/DC1

CMAJ 2009;180(12):1207-13
$\mathrm{D}$ uring the past 10 years, the health of people in Eastern Europe and the former Soviet Union has undergone changes very different from the health patterns seen in their Western counterparts. For example, mortality from cardiovascular disease has been decreasing continuously in the United States and many Western European countries, but it has increased or remained unchanged in many of the states of Eastern Europe. ${ }^{1}$

Analysis of this phenomenon has been hindered by insufficient information. The World Health Organization's MONICA project for monitoring cardiovascular mortality and risk factors considered only 6 Eastern European countries: Russia, Yugoslavia, Poland, Czechoslovakia, Hungary and the former East Germany. ${ }^{2}$ In geographic terms, Romania is the largest country in southeastern Europe, with a large population and substantial natural resources, ${ }^{3}$ but in some ways it is a "forgotten country." Few studies evaluating risks for cardiovascular disease have included Romania. Only 4 trials examining ST-segment elevation myocardial infarction have enrolled patients from Romania, ${ }^{4-6}$ and the numbers of patients were too few for reliable subgroup analysis.

Our aim was to investigate clinical characteristics, treatments and case fatality rates in an unselected population of patients admitted to hospital in Romania for ST-segment elevation myocardial infarction. In a secondary analysis, we analyzed sex differences in relation to treatment and outcome.

\section{Methods}

\section{Definition of hospital types}

At the time of our study, there were 4 main categories of hospitals in Romania: rural hospitals, town or municipal hospitals, district or county hospitals and tertiary referral hospitals. Rural hospitals (minimum of 120 beds) provided just internal medi-

From the Floreasca Emergency Hospital (Tatu-Chitoiu, Dorobantu); the Emergency University Hospital (Cinteza, Udeanu); the Emergency St. Pantelimon Hospital (Vintila), Bucharest, Romania; the Center of Cardiology (lonescu), Craiova, Romania; the Department of Cardiology (Craiu), County Hospital Constanta, Constanta, Romania; the Department of Internal Medicine (Burghina [deceased]), Municipality Hospital Timisoara, Timisoara, Romania; and the University of Bologna (Udeanu, Manfrini, Pizzi, Bugiardini), Bologna, Italy 
cine and pediatric services. Town and municipal hospitals (at least 250 beds) had departments of internal medicine, surgery, gynecology and obstetrics, and pediatrics. District and county hospitals (more than 400 beds) had these same departments and also departments of orthopedics, intensive care, ophthalmology and otorhinolaryngology. Tertiary referral hospitals had various cardiovascular and other surgical departments. ${ }^{7}$

\section{Participants}

At the time of the study, the Romanian Registry for ST-segment Elevation Myocardial Infarction encompassed 28 hospitals (21 county hospitals and 7 tertiary referral hospitals; Appendix 1, available at www.cmaj.ca/cgi/content/full/180/12/1207/DC2), each with an intensive coronary care unit and each providing medical reperfusion therapy. Only the 7 tertiary referral hospitals had cardiac catheterization facilities, for primary percutaneous coronary intervention. The participating centres were located in a geographic area that is representative of Romania as a whole (Appendix 2, available at www.cmaj.ca/cgi/content/full /180/12/1207/DC2). All of the hospitals were located in urban areas of at least 10000 people. The hospitals were able to access information about patients through the Health Access Data Assistance Center, an information-sharing system that allowed secure access to patients' health records. The hospitals periodically sent their data to the central server of the Romanian Society of Cardiology. We abstracted data on the clinical characteristics, in-hospital treatments and in-hospital deaths of patients from these medical records.

Patients were eligible for inclusion if they had symptoms consistent with acute cardiac ischemia and documented evidence of persistent ST-segment elevation or new left bundlebranch block on serial electrocardiograms and biomarkers of myocardial necrosis.

\section{Data collection and outcomes}

We collected the following data about eligible patients: demographic characteristics, cardiovascular risk factors, clinical history, electrocardiographic features, cardiac biomarkers, inhospital therapy, in-hospital death, fatal intracranial hemorrhage, and use of diagnostic and therapeutic interventional procedures. The treating physicians used serial electrocardiography (on admission and at 90 and 180 minutes) and measurements of biomarkers of myocardial necrosis (on admission and at 4, 9, 12, 16, 20, 24, 36, 48, 72 and 96 hours after admission to hospital) to adjudicate the discharge diagnosis of STsegment elevation myocardial infarction according to a standardized definition. ${ }^{8}$ We evaluated 4 process-of-care measures at admission: thrombolysis (streptokinase or fibrin-specific agents), antiplatelet agents (acetylsalicylic acid [ASA] or clopidogrel or both), anticoagulant drugs (unfractionated heparin and enoxaparin) and primary percutaneous coronary intervention. Our primary outcome was in-hospital mortality.

\section{Statistical analysis}

Data are presented as proportions, medians (interquartile range) or means (and standard deviations [SDs]) as appropriate. We combined data for secondary analyses. For discrete variables representing baseline characteristics, medical treat- ments and outcomes, we used $\chi^{2}$ tests to compare women with men and to compare patients treated in tertiary referral and county hospitals. We used the Fisher exact test to analyze categorical data when the sample sizes were small, such as for patients receiving primary percutaneous coronary interventions. We used the $t$ test for continuous variables. We used logistic regression analysis to estimate the adjusted odds ratios (ORs) and associated $95 \%$ confidence intervals (CIs). An OR of 1.0 means that the 2 variables were independent. OR values above 1.0 indicate an increasing effect of the independent variable on the dependent variable. OR values below 1.0 indicate an increasingly negative association between the 2 variables.

We included the following variables in the final model of our multivariable analysis: sex, age, risk factors (history of hypertension, diabetes, lipid disorders, smoking), clinical history (prior myocardial infarction), characteristics of the qualifying event (anterior acute myocardial infarction), Killip class $\geq 2$ at admission (indicating congestive heart failure), immediate in-hospital medical therapy (fibrinolysis, anticoagulant drugs, antiplatelet agents), type of hospital (tertiary referral v. county) and percutaneous coronary intervention. The patient group was subdivided by age into 4 groups: younger than 55 years, 55-64 years, 65-74 years and 75 years or older. ${ }^{9}$ Statistical significance was represented by $p$ values less than 0.05 .

\section{Results}

The Romanian Registry for ST-segment Elevation Myocardial Infarction prospectively enrolled 9288 consecutive patients discharged from the 28 hospitals between Jan. 1, 2000, and Jun. 30, 2007, with a diagnosis of ST-segment elevation myocardial infarction. We included in our analysis the patients $(n=83)$ who received fibrinolytic therapy before admission to hospital. We excluded patients who died before receiving any medication (71 men and 31 women). The total sample size was therefore 9186 . The mean age of the overall population was 63.8 (SD 11.8) years. The median time from onset of symptoms to hospital treatment was 230 (interquartile range $120-510)$ minutes. Only a small proportion of patients (1.9\%) underwent primary percutaneous coronary intervention. Of the 9186 patients, 4986 (54.3\%) had hypertension, 1974 (21.5\%) had diabetes, 3545 (38.6\%) had lipid disorders and 4653 $(50.7 \%)$ were smokers (Table 1$)$. The in-hospital mortality rate was $12.7 \%$ (1170 deaths).

\section{Comparisons by type of hospital}

The demographic characteristics of the patients differed significantly in relation to the type of hospital where they received treatment (Table 1). Specifically, patients admitted to tertiary referral hospitals were younger and more likely to be male. The percentage of patients who received appropriate early care was greater at the tertiary referral hospitals, which had revascularization capability, than at the county hospitals. Unadjusted and adjusted mortality rates determined by logistic regression indicated significantly lower in-hospital mortality among patients admitted to tertiary referral hospitals than among those admit- 
ted to county hospitals (unadjusted mortality rate $11.6 \% \mathrm{v}$. $15.3 \%$, OR $0.72,95 \%$ CI $0.64-0.82, p<0.001$; adjusted mortality rate $\mathrm{OR} 0.82,95 \% \mathrm{CI} 0.70-0.97, p=0.02$ ).

\section{Comparisons by sex}

Of the 9186 patients, 2893 (31.5\%) were women. The women were older, with a higher prevalence of hypertension and diabetes, but they were less likely to have a history of prior myocardial infarction or to be smokers (Table 2). A greater pro- portion of women presented with congestive heart failure (Killip class $\geq 2$ ) at the time of hospital admission.

\section{Time to presentation}

The median time from onset of symptoms to treatment was 265 (interquartile range 135 to 660) minutes for women and 195 (interquartile range 120 to 450$)$ minutes for men. A smaller proportion of women than men $(23.1 \%$ v. $34.4 \%, p<0.001)$ presented within 2 hours after onset of symptoms (Table 2). After adjust-

Table 1: Baseline characteristics for patients with ST-elevation myocardial infarction, according to hospital type

\begin{tabular}{|c|c|c|c|c|}
\hline \multirow[b]{2}{*}{ Characteristic } & \multicolumn{3}{|c|}{ Hospital type; no. (\%) of patients* } & \multirow[b]{2}{*}{$p$ value $\ddagger$} \\
\hline & $\begin{array}{l}\text { All patients } \\
n=9186\end{array}$ & $\begin{array}{c}\text { Tertiary referral } \\
\text { hospitalst } \\
n=6214\end{array}$ & $\begin{array}{c}\text { County hospitals } † \\
n=2918\end{array}$ & \\
\hline Age, yr, mean (standard deviation) & $63.8(11.8)$ & $61.9(12.8)$ & $63.3(12.3)$ & $<0.001$ \\
\hline Sex, male & $6293(68.5)$ & 4377 (70.4) & $1875(64.3)$ & $<0.001$ \\
\hline Diabetes mellitus & $1974(21.5)$ & 1357 (21.8) & 598 (20.5) & 0.14 \\
\hline Lipid disorders & $3545(38.6)$ & 2597 (41.8) & $920(31.5)$ & $<0.001$ \\
\hline Current smoker & $4653(50.7)$ & $3377 \quad(54.3)$ & $1252(42.9)$ & $<0.001$ \\
\hline Prior myocardial infarction & $935(10.2)$ & $649(10.4)$ & $282(9.7)$ & 0.24 \\
\hline Time from symptom onset to admission, h§ & $n=7863$ & $n=5852$ & $n=1960$ & \\
\hline$\leq 2$ & $2433(30.9)$ & $1845 \quad(31.5)$ & $571(29.1)$ & 0.040 \\
\hline$>2-6$ & $2957(37.6)$ & $2245 \quad(38.4)$ & $694(35.4)$ & 0.010 \\
\hline$>6-12$ & $1047(13.3)$ & $692(11.8)$ & $344(17.6)$ & $<0.001$ \\
\hline$>12$ & $1426(18.1)$ & $1070(18.3)$ & $351(17.9)$ & 0.71 \\
\hline \multicolumn{5}{|l|}{ Time from symptom onset to thrombolysis, h§ } \\
\hline$\leq 2$ & $1870(23.8)$ & $1420(24.3)$ & $434(22.1)$ & 0.010 \\
\hline$>2-6$ & $2059(26.2)$ & $1610 \quad(27.5)$ & $433(22.1)$ & $<0.001$ \\
\hline$>6-12$ & $309 \quad$ (3.9) & $250 \quad(4.3)$ & $50(2.6)$ & $<0.001$ \\
\hline Clopidogrel & $157 \quad(1.7)$ & $123 \quad(2.0)$ & $34(1.2)$ & 0.007 \\
\hline Acetylsalicylic acid and clopidogrel & $2162(23.5)$ & $1635(26.3)$ & $518(17.8)$ & $<0.001$ \\
\hline Other & 166 (1.8) & $157 \quad(2.5)$ & $7 \quad(0.2)$ & $<0.001$ \\
\hline Primary percutaneous intervention & 179 (1.9) & $179 \quad(2.9)$ & 0 & $<0.001$ \\
\hline In-hospital mortality & $1170(12.7)$ & 721 (11.6) & $446(15.3)$ & $<0.001$ \\
\hline
\end{tabular}

*Unless otherwise indicated.

tFor 54 patients, data about type of hospital (tertiary referral or county) were missing.

¥For comparison between patients admitted to tertiary referral hospitals and those admitted to county hospitals.

§Data on the time to treatment were available for 7863 (85.6\%) of all study patients and for 7812 (85.5\%) of those for whom type of hospital (tertiary referral or county) was known; of the latter group, data on time to treatment were available for 5852 of those treated at tertiary referral hospitals and 1960 of those treated at county hospitals. Among patients who received thrombolytic therapy, time from symptom onset to thrombolysis was available for 4311 patients ( 3343 of those treated at tertiary referral hospitals, 926 of those treated at county hospitals and 42 of those for whom type of hospital was unknown). 
ment for age, risk factors, clinical history and clinical characteristics of the qualifying event, female sex was still an independent negative predictor of time from onset of symptoms to thrombolysis within 2 hours (OR 0.68, 95\% CI 0.60-0.77, $p<0.001$ ). An important aspect of this analysis was the inclusion of a substantial number of elderly patients ( 75 years of age or older) who presented "late" (more than 12 hours after onset of symptoms). Late time to treatment was more evident among both elderly women (207 of 759 patients [27.3\%]) and elderly men (169 of 657 patients [25.7\%]) than among patients less than 75 years of age (314 of 1664 women [18.9\%], 736 of 4783 men [15.4\%]).

\section{Thrombolysis and concomitant medications}

Significantly lower proportions of women received anticoagulants, antiplatelet agents and fibrinolytic therapy (Table 2). There was no difference in the type of fibrinolytic agent used for women and men: streptokinase, 68.8\% (811/1179) v. $69.2 \%$ (2330/3367); fibrin-specific agents, 31.2\% (368/1179) v. $30.8 \%$ (1037/3367). Multivariable analysis showed that female sex was a negative independent predictor of administration of thrombolysis (OR $0.84,95 \%$ CI $0.76-0.93, p=0.001$ ) and antiplatelet agents (OR 0.81, 95\% CI 0.69-0.95, $p=0.01$ ) (Figure 1). Conversely, after adjustment for covariates, the

Table 2: Baseline characteristics for patients with ST-elevation myocardial infarction, according to sex

\begin{tabular}{|c|c|c|c|}
\hline \multirow[b]{2}{*}{ Characteristic } & \multicolumn{2}{|c|}{ Sex; no. (\%) of patients* } & \multirow[b]{2}{*}{$p$ value $\dagger$} \\
\hline & $\begin{array}{c}\text { Men } \\
n=6293\end{array}$ & $\begin{array}{l}\text { Women } \\
n=2893\end{array}$ & \\
\hline Age, yr, mean (SD) & $59.7(12.3)$ & $68.0(11.4)$ & $<0.001$ \\
\hline \multicolumn{4}{|l|}{ Medical history } \\
\hline Hypertension & $3151(50.1)$ & $1835(63.4)$ & $<0.001$ \\
\hline Diabetes mellitus & $1265(20.1)$ & 709 (24.5) & $<0.001$ \\
\hline Lipid disorders & $2443(38.8)$ & $1102(38.1)$ & 0.52 \\
\hline Current smoker & $3753(59.6)$ & $900(31.1)$ & $<0.001$ \\
\hline Prior myocardial infarction & $682(10.8)$ & $253 \quad(8.7)$ & 0.002 \\
\hline \multicolumn{4}{|l|}{ Characteristics of the qualifying event } \\
\hline Anterior acute myocardial infarction & $3161(50.2)$ & $1476(51.0)$ & 0.48 \\
\hline Killip class $\geq 2$ & $1914(30.4)$ & $1129(39.0)$ & $<0.001$ \\
\hline Time from symptom onset to admission, $\mathrm{h} \ddagger$ & $n=5440$ & $n=2423$ & \\
\hline$\leq 2$ & $1874(34.4)$ & $559(23.1)$ & $<0.001$ \\
\hline$>2-6$ & $2005(36.9)$ & $952(39.3)$ & $<0.001$ \\
\hline$>6-12$ & $656(12.1)$ & $391(16.1)$ & $<0.001$ \\
\hline$>12$ & $905(16.6)$ & $521(21.5)$ & $<0.001$ \\
\hline \multicolumn{4}{|l|}{ Time from symptom onset to thrombolysis, $\mathrm{h} \ddagger$} \\
\hline$\leq 2$ & $1492(27.4)$ & $378(15.6)$ & $<0.001$ \\
\hline$>2-6$ & $1452(26.7)$ & $607(25.1)$ & 0.13 \\
\hline$>6-12$ & $216 \quad(4.0)$ & $93 \quad(3.8)$ & 0.67 \\
\hline$>12$ & $45 \quad(0.8)$ & $28 \quad(1.2)$ & 0.08 \\
\hline In-hospital medication & $n=6293$ & $n=2893$ & \\
\hline Thrombolytic therapy & $3367(53.5)$ & $1179(40.8)$ & $<0.001$ \\
\hline Anticoagulants & $5989(95.2)$ & $2703(93.4)$ & 0.001 \\
\hline Antiplatelet drugs & $5741(91.2)$ & $2555(88.3)$ & $<0.001$ \\
\hline Acetylsalicylic acid & $3886(61.8)$ & $1925(66.5)$ & $<0.001$ \\
\hline Clopidogrel & 114 (1.8) & $43 \quad(1.5)$ & 0.08 \\
\hline Acetylsalicylic acid and clopidogrel & $1614(25.6)$ & $548(18.9)$ & $<0.001$ \\
\hline Other & $127 \quad(2.0)$ & $39 \quad(1.3)$ & 0.010 \\
\hline Primary percutaneous intervention & $136 \quad(2.2)$ & $43 \quad(1.5)$ & 0.030 \\
\hline $\begin{array}{l}\text { Primary percutaneous intervention within } \\
90 \text { minutes from symptom onset }\end{array}$ & $35 \quad(0.6)$ & $2(0.1)$ & $<0.001$ \\
\hline In-hospital mortality & $641(10.2)$ & $529(18.3)$ & $<0.001$ \\
\hline
\end{tabular}

*Unless otherwise indicated.

tFor comparison between men and women.

‡Data on time to treatment were available for $5440(86.4 \%)$ men and $2423(83.8 \%)$ women. Among patients who received thrombolytic therapy, time from symptom onset to thrombolysis was available for 3205 men (58.9\%) and 1106 women (45.6\%). 
chance of receiving anticoagulant agents was the same for women and men (OR 0.84, 95\% CI, 0.68-1.03, $p=0.10$ ) (Figure 1).

\section{Primary percutaneous coronary intervention}

Primary percutaneous coronary intervention is more effective than thrombolysis in the management of acute myocardial infarction..$^{10}$ However, few patients in this study received primary percutaneous angioplasty $(n=179$; Table 1$)$. Primary percutaneous coronary intervention was about twice as frequent among men as among women (Table 2).

Data on time to treatment were available for 5852 of the patients treated at tertiary referral centres, but just 1052 $(18.0 \%)$ of these presented on time (i.e., within 90 minutes of symptom onset). Within this group, only 37 patients $(3.5 \%$; 35 men and 2 women) received primary percutaneous coronary intervention.

\section{Medical therapy according to sex and age groups}

We tested for a sex-by-age interaction for the use of acute treatments but found no significant interactions. In the adjusted analysis, treatment rates differed according to sex, with rates of use of fibrinolytic and antiplatelet agents being lower among women than men in all age groups.

\section{Predictors of mortality}

The number of patients who died in hospital was 1170 . Several clinical and demographic characteristics were independently predictive of an increase in this adverse outcome by univariable and multivariable analysis (Table 3). Multivariable logistic regression analysis showed that the strongest independent predictors of mortality were heart failure (Killip class $\geq 2$ ), prior myocardial infarction, anterior acute myocardial infarction, female sex, older age, type of hospital and lack of acute care medications (antiplatelet agents, anticoagulants and thrombolytic therapy within 2 hours after onset of symptoms). The adjusted odds of death associated with use of thrombolytic therapy in the overall population was not significant (OR 0.96, 95\% CI 0.81-1.13). Adjustment for time to treatment within 6 hours did not significantly change the odds of death (OR $0.87,95 \%$ CI 0.74-1.02). Use of antiplatelet agents was associated with the greatest reduction in odds of mortality ( $74 \%$ reduction).

\section{Cerebrovascular events}

There were no substantial differences in the rates of nonfatal intracranial hemorrhage among women and men, both for patients 75 years of age or older (8/918 [0.9\%] v. 8/790 [1.0\%]) and for those less than 75 years of age (10/1975 [0.5\%] v. $33 / 5503[0.6 \%])$. In addition, there was no significant difference between women and men in the number of ischemic strokes in these 2 age groups (5/918 [0.5\%] v. 3/790 [0.4\%] for patients 75 years of age or older; 2/1975 [0.1\%] v. $11 / 5503[0.2 \%]$ for patients less than 75 years of age).

\section{Interpretation}

We observed low use of evidence-based therapy, both medications and interventions, for Romanian patients with STsegment elevation myocardial infarction. The quality of care was suboptimal in both county and tertiary referral hospitals. Between $10 \%$ and $20 \%$ of patients who received treatment in county hospitals did not receive antiplatelet agents, and $62 \%$ did not receive reperfusion therapy. Patients who received treatment at tertiary referral hospitals were more likely to receive appropriate medical therapy, but a large percentage of them did not undergo primary percutaneous interventions. When we limited our analysis of use of primary percutaneous interventions to patients who presented to a tertiary referral hospital within 90 minutes after onset of symptoms, we found that only $3.5 \%$ of these patients received such interventions. Excess in-hospital mortality was more pronounced among women. Delayed time to onset of treatment and lower use of primary coronary intervention, thrombolysis, ASA and anticoagulants may have all contributed to higher in-hospital mortality for women.

The rural inhabitants of Romania represent more than $50 \%$ of the country's total population. Usual practice dictates that patients be transferred to regional county referral hospitals or to tertiary referral hospitals, where intensive coronary care

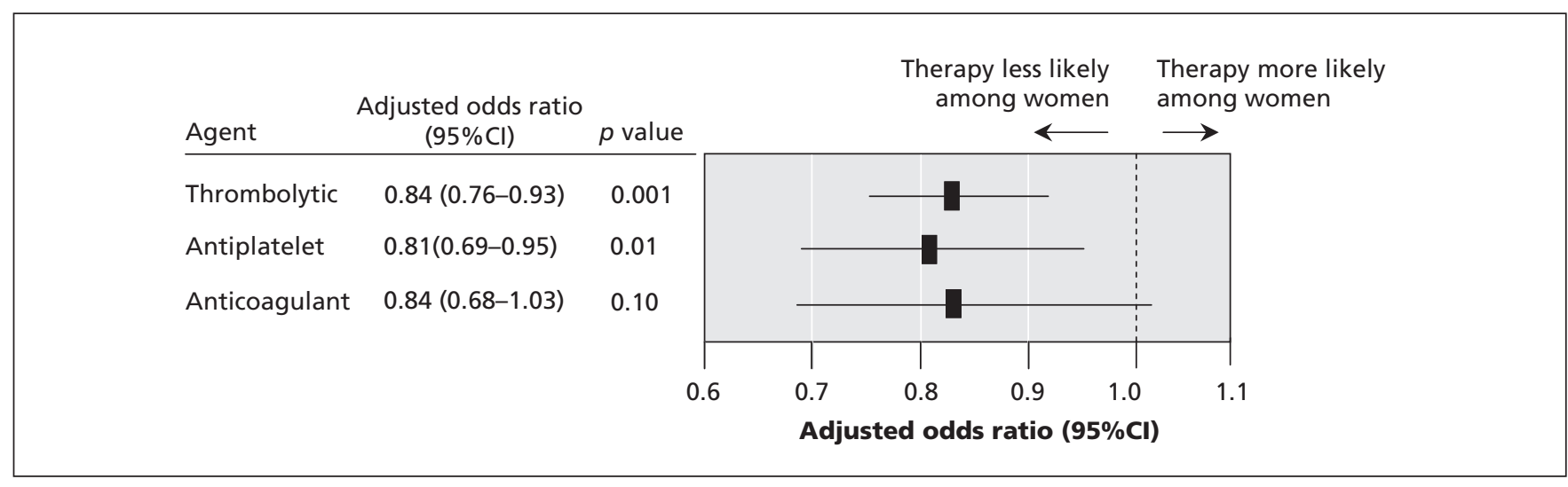

Figure 1: Odds ratios for acute medical therapy (with men as the reference group) in a multivariable model, after adjustment for age, risk factors, clinical history, characteristics of the qualifying event, primary percutaneous intervention and type of hospital. Note: $\mathrm{Cl}=$ confidence interval. 
units and advanced technologies are available. ${ }^{11}$ In this study, we examined in-hospital mortality rates after myocardial infarction in 21 county hospitals and 7 tertiary referral hospitals in Romania. We interpreted the mortality rates in light of the available evidence on the burden of traditional risk factors and practice patterns for cardiovascular medical care in Western Europe and the United States.

We found major differences in practice patterns between Romania and many other industrialized countries, specifically the Euro Heart Survey I and II for acute coronary syndromes ${ }^{12,13}$ and the National Registry of Myocardial Infarction-5 in the United States. ${ }^{14,15}$ The patients in our study were similar in age to those in the Euro Heart Survey I and II (mean 63.8 years v. range 62.5-63.4 years) and were 2.6 years younger than those in the US National Registry of Myocardial Infarction-5. Apart from smoking, traditional risk factors were more frequent in the Euro Heart Survey I and II and the US National Registry of Myocardial Infarction-5 than in the Romanian Registry for ST-segment Elevation Myocardial Infarction population. For the patients in our registry, the average time to receive thrombolysis was longer than times reported in the Euro Heart Survey I and II and the US National Registry of Myocardial Infarction-5 (mean 230 minutes v. range 125-210 minutes). Of the patients in the Romanian Registry for ST-segment Elevation Myocardial Infarction, $50.5 \%$ received some form of reperfusion therapy; the corresponding figure in the Euro Heart Survey II was $63.9 \% .^{13}$ The rate of primary percutaneous coronary intervention was lower

Table 3: Predictors of in-hospital mortality among patients with ST-elevation myocardial infarction

\begin{tabular}{|c|c|c|c|c|}
\hline \multirow{3}{*}{$\begin{array}{l}\text { Variable } \\
\text { Age }\end{array}$} & \multicolumn{4}{|c|}{ Odds ratio ( $95 \%$ confidence interval) } \\
\hline & \multicolumn{2}{|c|}{$\begin{array}{c}\text { Unadjusted } \\
n=9186\end{array}$} & \multicolumn{2}{|r|}{$\begin{array}{l}\text { Adjusted } \\
n=7794\end{array}$} \\
\hline & 1.05 & $(1.04-1.06) *$ & 1.03 & $(1.02-1.04) \dagger$ \\
\hline Sex, female & 1.97 & $(1.74-2.24) \dagger$ & 1.33 & $(1.13-1.56) \dagger$ \\
\hline \multicolumn{5}{|l|}{ Medical history } \\
\hline Hypertension & 0.94 & $(0.83-1.06)$ & 0.77 & $(0.66-0.91) *$ \\
\hline Diabetes mellitus & 1.35 & $(1.17-1.56) \dagger$ & 1.16 & $(0.98-1.39)$ \\
\hline Lipid disorders & 0.60 & $(0.52-0.68) \dagger$ & 0.70 & $(0.60-0.83) \dagger$ \\
\hline Current smoker & 0.49 & $(0.42-0.54) \dagger$ & 0.80 & $(0.67-0.95)^{*}$ \\
\hline Prior myocardial infarction & 2.01 & $(1.70-2.39) \dagger$ & 1.67 & $(1.36-2.05) \dagger$ \\
\hline \multicolumn{5}{|l|}{ Characteristics of the qualifying event } \\
\hline Anterior acute myocardial infarction & 1.58 & $(1.39-1.79) \dagger$ & 1.44 & $(1.24-1.68) \dagger$ \\
\hline Killip class $\geq 2$ & 5.10 & $(4.48-5.82) \dagger$ & 4.27 & $(3.64-5.00) \dagger$ \\
\hline Tertiary referral hospital & 0.72 & $(0.64-0.82) \dagger$ & 0.82 & $(0.70-0.97) *$ \\
\hline \multicolumn{5}{|l|}{ Acute treatment } \\
\hline Thrombolysis within $2 \mathrm{~h}$ & 0.51 & $(0.42-0.61) \dagger$ & 0.75 & $(0.61-0.92) *$ \\
\hline Anticoagulant drugs & 0.66 & $(0.61-0.72) \dagger$ & 0.65 & $(0.58-0.72) \dagger$ \\
\hline Antiplatelet drugs & 0.31 & $(0.26-0.37) \dagger$ & 0.26 & $(0.21-0.33) \dagger$ \\
\hline Primary percutaneous intervention & 0.57 & $(0.33-0.99)^{*}$ & 0.87 & $(0.45-1.68)$ \\
\hline
\end{tabular}

${ }^{*} p<0.05$

$+p<0.001$. among patients in the Romanian Registry for ST-segment Elevation Myocardial Infarction than among patients in the Euro Heart Survey II (1.9\% v. 36.4\%), and the rate of thrombolytic treatment was higher ( $49.6 \%$ v. $27.5 \%)$. Crude inhospital mortality was markedly higher for the entire cohort of the Romanian Registry for ST-segment Elevation Myocardial Infarction than for the cohorts of the Euro Heart Survey I and II and the US National Registry of Myocardial Infarction$5(12.7 \%$ v. range from $5.3 \%$ to $8 \%)$. Our data suggest that the differences in mortality between high-income countries and Romania were not due to differences in the global burden of risk factors or age, but were probably due to differences in treatments and related factors such as time to hospital admission and care.

Our results underscore the importance of evaluating the outcomes and effectiveness of how and where health care services are delivered. In particular, we found significant differences in mortality between tertiary referral and county hospitals. The unadjusted survival advantage was about $4 \%$ for tertiary referral hospitals relative to county hospitals (OR $0.72,95 \%$ CI 0.64-0.82). Differences in mortality were attenuated but not eliminated by adjustment for patient characteristics, time to thrombolysis and receipt of percutaneous coronary intervention and medical therapy (OR $0.82,95 \% \mathrm{CI}$ $0.70-0.97)$. As such, other factors may be important in explaining the association. For example, unmeasured patient or hospital characteristics might have affected our findings. Higher rates of misdiagnosis, worse drug information services, less participation in medical rounds and longer work hours for staff nurses and doctors may have converged to create potentially hazardous conditions for patients in the county hospitals. ${ }^{16}$

Successful reperfusion between 30 minutes and 2 hours after onset of symptoms can result in considerable myocardial salvage and improvements in outcome after 30 days. ${ }^{17-21}$ In the Romanian Registry for ST-segment Elevation Myocardial Infarction, the primary outcome was in-hospital mortality. Only a minority of women in our study $(23.1 \%)$ encountered medical personnel within 2 hours, and, after adjustment for confounders, the rate of cardiovascular death was greater for women than men. Nevertheless, lack of timely fibrinolytic therapy is insufficient to explain the excess risk of death among women. In this study, after adjustment for any clinical confounders, low rate of use of antiplatelet drugs was an independent predictor of death and could have contributed to the higher case-fatality rate among women.

The reasons for lower use of antiplatelet agents for women are unknown. ${ }^{22-27}$ Some studies have shown 
that sex differences in treatment of myocardial infarction may relate to the women's older age. ${ }^{28}$ However, we found that differences between the sexes in the use of antiplatelet agents did not differ according to age. Specifically, women were less likely than men to receive clopidogrel alone or in combination with ASA. We suggest that women were less likely to receive prompt diagnosis of myocardial infarction at admission and were therefore less likely to receive aggressive medical therapy.

The main limitation of our study was a lack of data about some variables that are potentially important in deciding whether to administer thrombolytic therapy or perform primary percutaneous interventions, including contraindications to medical therapy and interventions. However, few medical records list contraindications to the recommended care, so identifying patients who are eligible for treatment is difficult in any observational analysis. ${ }^{29}$

We found that the care Romanian patients with STelevation myocardial infarction was characterized by limited use of appropriate medications and interventions. At the time of the study, tertiary referral units did not routinely offer immediate cardiac catheterization services, and it would be expensive to set up such services. However, county hospitals should improve the essential elements of care for these patients. In particular, measures to minimize the time to initiation of reperfusion therapy are urgently required.

\section{This article has been peer reviewed.}

\section{Competing interests: None declared.}

Contributors: All of the authors contributed to the conception and design of the study. Gabriel Tatu-Chitoui, Mircea Cinteza, Maria Dorobantu, Marius Vintila, Dominic D. Ionescu, Elvira Craiu and Daniel Burghina collected the data, and all of the authors contributed to the analysis and interpretation of the data. Raffaele Bugiardini drafted the article. All of the authors revised it critically for important intellectual content and approved the final version submitted for publication.

Funding: The analyses for this study were carried out at the University of Bologna. The Partnership and Cooperation Agreements between the University of Bologna and the University of Bucharest were part of the framework for relations between the European Union and the countries of Eastern Europe and Central Asia (Lifelong Learning Program).

\section{REFERENCES}

1. World Health Organization, Regional Office for Europe. The European health report 2002. Copenhagen (Denmark): The Organization; 2002. p. 7-45.

2. Tunstall-Pedoe H, Vanuzzo D, Hobbs M, et al. Estimation of contribution of changes in coronary care to improving survival, event rates, and coronary heart disease mortality across the WHO MONICA project populations. Lancet 2000;355:688-700.

3. U.S. government assistance to Eastern Europe under the Support for East European Democracy (SEED) Act. Washington (DC): US Department of State, Bureau of European and Eurasian Affairs; 2004. p. 68-113.

4. Gurjeva OS, Bukhman G, Murphy S, et al. Treatment and outcomes of eastern Europeans with coronary syndromes in OPUS-TIMI 16. Int J Cardiol 2005;100:101-7.

5. Kramer JM, Newby LK, Chang WC, et al. International variation in the use of evidence-based medicines for acute coronary syndromes. Eur Heart J 2003;24 2133-41.
6. Mega JL, Morrow DA, Östör E, et al. Outcomes and optimal antithrombotic therapy in women undergoing fibrinolysis for ST-elevation myocardial infarction. Circulation 2007; $115: 2822-8$.

7. National Institute of Statistics. Romanian statistical yearbook. Bucharest (Romania): The Institute; 2006. p. 73-9.

8. Thygesen K, Alpert JS, White HD, et al.; Joint ESC/ACCF/AHA/WHF Task Force for the Redefinition of Myocardial Infarction, et al. Universal definition of myocardial infarction. Circulation 2007;116:2634-53.

9. Vaccarino V, Parsons L, Every NR, et al. Sex-based differences in early mortality after myocardial infarction. N Engl J Med 1999;341:217-25.

10. Hochman JS, Lamas GA, Buller CE, et al. Coronary intervention for persistent occlusion after myocardial infarction. N Engl J Med 2006;355:2395-407.

11. James PA, Li P, Ward MM. Myocardial infarction mortality in rural and urban hospitals: rethinking measures of quality of care. Ann Fam Med 2007;5:105-11.

12. Rosengren A, Wallentin L, K Gitt A, et al. Sex, age, and clinical presentation of acute coronary syndromes. Eur Heart J 2004;25:663-70.

13. Mandelzweig L, Battler A, Boyko V, et al. The second Euro Heart Survey on acute coronary syndromes: characteristics, treatment, and outcome of patients with ACS in Europe and the Mediterranean Basin in 2004. Eur Heart J 2006;27:2285-93.

14. Rogers WJ, Frederick PD, Stoehr E, et al. Trends in presenting characteristics and hospital mortality among patients with ST elevation and non-ST elevation myocardial infarction in the National Registry of Myocardial Infarction from 1990 to 2006. Am Heart J 2008;156:1026-34.

15. Gibson CM, Pride YB, Frederick PD, et al. Trends in reperfusion strategies, doorto-needle and door-to-balloon times, and in-hospital mortality among patients with ST-segment elevation myocardial infarction enrolled in the National Registry of Myocardial Infarction from 1990 to 2006. Am Heart J 2008;156:1035-44.

16. Bara AC, van den Heuvel WJ, Maarse JA. Reforms of health care system in Romania. Croat Med J 2002;43:446-52.

17. Fibrinolytic Therapy Trialists' (FTT) Collaborative Group. Indications for fibrinolytic therapy in suspected acute myocardial infarction: collaborative overview of early mortality and major morbidity results from all randomised trials of more than 1000 patients. Lancet 1994;343:311-22.

18. Boersma E, Maas AC, Deckers JW, et al. Early thrombolytic treatment in acute myocardial infarction: reappraisal of the golden hour. Lancet 1996;348:771-5.

19. Morrison LJ, Verbeek PR, McDonald AC, et al. Mortality and prehospital thrombolysis for acute myocardial infarction: a meta-analysis. JAMA 2000;283:2686-92.

20. Steg PG, Bonnefoy E, Chabaud S, et al.; Comparison of Angioplasty and Prehospital Thrombolysis In Acute Myocardial Infarction (CAPTIM) Investigators. Impact of time to treatment on mortality after prehospital fibrinolysis or primary angioplasty: data from the CAPTIM randomized clinical trial. Circulation 2003;108:2851-6.

21. Antman EM, Hand M, Armstrong PW, et al. 2007 focused update of the ACC/AHA 2004 Guidelines for the Management of Patients with ST-Elevation Myocardial Infarction: a report of the American College of Cardiology/American Heart Association Task Force on Practice Guidelines. Circulation 2008;117:296-329.

22. Kober L, Torp-Pedersen C, Ottesen M, et al. Influence of gender on short- and longterm mortality after acute myocardial infarction. Am J Cardiol 1996;77:1052-6.

23. Yarzebski J, Col N, Pagely P, et al. Gender differences and factors associated with the receipt of thrombolytic therapy in patients with acute myocardial infarction: a community-wide perspective. Am Heart J 1996;131:43-50.

24. Kudenchuk PJ, Maynard C, Martin JS, et al. Comparison of presentation, treatment, and outcome of acute myocardial infarction in men versus women. Am J Cardiol 1996;78:9-14.

25. Maynard C, Althouse R, Cerqueira M, et al. Underutilization of thrombolytic therapy in eligible women with acute myocardial infarction. Am J Cardiol 1991;68:529-30.

26. McLaughlin TJ, Soumerai SB, Willison DJ, et al. Adherence to national guidelines for drug treatment of suspected acute myocardial infarction: evidence for undertreatment in women and elderly. Arch Intern Med 1996;156:799-805.

27. Gurwitz JH, Gore JM, Goldberg RJ, et al. Recent age-related trends in the use of thrombolytic therapy in patients who have had acute myocardial infarction: National Registry of Myocardial Infarction. Ann Intern Med 1996;124:283-91.

28. Vaccarino V, Rathore SS, Wenger NK, et al. Sex and racial differences in the management of acute myocardial infarction, 1994 through 2002. N Engl J Med 2005;353: 671-82.

29. Braunwald E, Antman EM, Beasley JW, et al. ACC/AHA guidelines for the management of patients with unstable angina and non-ST-segment elevation myocardial infarction: executive summary and recommendations: a report of the American College of Cardiology/American Heart Association Task Force on Practice Guidelines (Committee on Management of Patients With Unstable Angina). Circulation 2000;102:1193-209.

Correspondence to: Dr. Raffaele Bugiardini, Dipartimento di Medicina Interna, dell'Invecchiamento e Malattie Nefrologiche (Padiglione 11), University of Bologna, Via Massarenti 9, 40138 Bologna, Italy; fax 39 051347290; raffaele.bugiardini@unibo.it 